\title{
O PROBLEMA DE INTERPRETAÇÃO DA KÁTHARSIS NA POÉTICA
}

\author{
Mariane Farias de Oliveira ${ }^{1}$ \\ "Ao tornar mais sutil, fina e delicada a consideração de \\ algo a um certo título que é parte constitutiva da emoção, \\ a tragédia nos dá eo ipso um deleite, a saber, o de \\ apreender em sua riqueza os labirintos da emoção \\ humana. Não se trata de remover nada, nem mesmo de \\ purificar, mas de conhecer com mais precisão a anatomia \\ de uma paixão." (ZINGANO, 1998)
}

\begin{abstract}
RESUMO
Ao tentarmos compreender a definição aristotélica de tragédia no capítulo 6 da Poética, nos deparamos com o problema de interpretação da kátharsis. Segundo tal definição, ao suscitar o temor e a piedade em seu público, a tragédia "proporcionaria uma kátharsis" em relação a essas emoções. A partir de uma utilização do termo que surge na Política VIII, 7 Jonathan Lear aponta três importantes possibilidades de interpretação que devem ser consideradas: a kátharsis enquanto uma purgação advinda do êxtase religioso e da cura medicinal, a kátharsis como purificação a partir da transformação do sofrimento em prazer durante a performance trágica e a kátharsis enquanto educação das emoções. Pretendo apresentar uma qualificação da noção de kátharsis como "educação das emoções" que mostre que, além de proporcionar uma educação moral, a kátharsis também instancia a educação estética do homem através do "prazer específico da tragédia".
\end{abstract}

Palavras-chave: Kátharsis; Aristóteles; Poética; tragédia.

\begin{abstract}
Trying to understand the Aristotelian definition of tragedy in Chapter 6 of the Poetics, we face the problem of interpretation of kátharsis. Under that definition, to arouse fear and pity in his audience, the tragedy "would provide a kátharsis" in relation to these emotions. From a use of the term that appears in Politics VIII, 7 Jonathan Lear points out three important possibilities of interpretation that should be considered: kátharsis as a purgation arising ecstasies of religious and medicinal healing, kátharsis as a purification from the transformation pleasure in the suffering during the tragic performance, and katharsis as education of the emotions. I want to present a qualification of the notion of katharsis as "education of emotions" that shows that in addition to providing a moral education, kátharsis also instantiates the aesthetic education of man through the "specific pleasure of tragedy."
\end{abstract}

Keywords: Kátharsis; Aristotle; Poetics; tragedy.

\footnotetext{
${ }^{1}$ Graduanda em Filosofia pela Universidade Federal do Rio Grande do Sul - UFRGS
} 


\section{Introdução}

Na introdução à sua tradução da Poética, Gerald Else (1970, p. 4) escreveu que essa obra consiste na tentativa de responder a duas questões: o que a poesia é e o que ela pode fazer. Nosso trabalho concerne mais especificamente à segunda questão, pois trata do efeito da tragédia sobre seus espectadores. Porém, ao obtermos uma resposta para tal efeito acreditamos que estamos no caminho de responder também à primeira pergunta por dois motivos: o problema aqui investigado, a saber, a kátharsis, encontrase justamente no capítulo em que Aristóteles deseja apresentar uma definição de tragédia e, além disso, conhecer o que a tragédia pode fazer clarifica nossa visão sobre seu estatuto no pensamento aristotélico, o que também diz respeito ao que ela é.

Ao tentarmos compreender a definição aristotélica de tragédia no capítulo 6 da Poética, nos deparamos com o problema de interpretação da kátharsis. Segundo tal definição, ao suscitar o temor e a piedade em seu público, a tragédia "proporcionaria uma kátharsis" através dessas emoções:

A tragédia é a imitação de uma ação importante e completa, de certa extensão; deve ser composta num estilo tornado agradável pelo emprego separado de cada uma de suas formas; na tragédia, a ação é apresentada, não com a ajuda de uma narrativa, mas por atores. Suscitando a compaixão e o terror, a tragédia tem por efeito obter a purgação [kátharsis] dessas emoções. (1449b2530).

É difícil definir a natureza deste processo. Um indício textual para interpretação, ao qual muitos comentadores se filiam, é o aparecimento do mesmo termo no capítulo 7 do livro VIII da Política, no qual Aristóteles, ao delegar três funções distintas à mousiké ${ }^{2}$ - educação, entretenimento e entretenimento educativo -, comenta os possíveis efeitos das melodias catárticas nas pessoas (a saber: entretenimento intelectual/educativo, relaxamento e recreação), sem deixar claro em qual desses sentidos e de que maneira exata a kátharsis pode ser entendida:

\footnotetext{
${ }^{2}$ A noção de mousiké não compreende apenas o que conhecemos como "música", mas também a poesia, incluindo o drama, que, por sua vez, pode ser acompanhado ou não por uma performance. Cf. 1340a14. 
Já aceitamos a classificação das melodias feita por alguns filósofos, ou seja, melodias de efeito moral, de efeitos práticos e inspiradoras de entusiasmo, distribuindo as várias harmonias entre estas classes de melodias como sendo naturalmente afins a uma delas, diremos que o emprego da música não se limita a uma única espécie de utilidade, e que, ao contrário deve haver muitas. Com efeito, ela pode servir à educação $\mathrm{e}$ à catarse - no momento usamos o termo "catarse" sem maiores explicações, mas voltaremos a discutir mais claramente o significado que lhe atribuímos [...]. É evidente que devemos usar todas as harmonias, sem todavia empregá-las de maneira idêntica, e sim recorrendo às de efeito moral para fins educativos e às de efeitos práticos e inspiradoras de entusiasmo para audição quando executadas por outros. Esta predisposição a ser afetado pela música, tão intensa em certas pessoas, existe em todas elas, e só difere para menos ou para mais - por exemplo, a piedade, o temor e também o entusiasmo são manifestações dela; de fato, algumas pessoas são muito susceptíveis a estas formas de emoção, e sob a influência da música sacra vemo-las, quando ouvem melodias que lhes excitam a alma, lançadas num estado semelhante ao dos doentes que encontram um remédio capaz de livrá-los de seus males; a mesma sensação devem experimentar as pessoas sob influência da piedade e do temor e as outras pessoas emotivas em geral, na proporção em que elas são susceptíveis a tais emoções, e todas devem passar por uma catarse e ter uma sensação agradável de alívio; da mesma forma as melodias catárticas proporcionam um sentimento de prazer sadio aos homens. (1342b530)

A partir deste trecho da Política, Jonathan Lear (1992, p. 312) aponta três importantes possibilidades de interpretação que devem ser consideradas: a kátharsis como uma purgação resultando na cura medicinal, a kátharsis como purificação ritualística e religiosa e, finalmente, a kátharsis como educação dos sentimentos.

Lear refuta as duas primeiras maneiras de interpretação com o argumento de que, grosso modo, o homem educado é considerado o público ideal das tragédias para Aristóteles. Por sua vez, ainda que o homem educado vivencie paixões excessivas, ele não as tem como hábitos em seu caráter, pois a sabedoria prática o habilita a controlar as paixões. Para Lear, isso bastaria para refutar as duas primeiras interpretações. Porém, ainda gera um problema: como interpretar "educação das emoções", uma vez que o público que Aristóteles sugere ser o público da tragédia é composto já por homens adultos e educados? Em razão desse problema, Lear termina por abandonar todos estes sentidos de kátharsis e propor uma leitura intermediária ou "compatibilizada" do termo. Porém, neste momento, abandonamos a leitura de Lear para propor que a educação das emoções pode, sim, ser direcionada a homens adultos e educados, o que também é uma maneira de responder às suas refutações. Isso acontece porque uma educação das virtudes não pode se dar em casos abstratos e gerais, mas sim na educação de uma 


\section{O problema da interpretação da Kátharsis na Poética}

sensibilidade para distinguir o modo correto de agir considerando as circunstâncias da ação. É exatamente pelo motivo não estar na agenda da ética das virtudes encontrar imperativos com pretensão de validade universal que Aristóteles parece compreender o papel fundamental da arte trágica para educar a sensibilidade que habilita o público a reconhecer e agir virtuosamente nos casos singulares que as tragédias nos apresentam.

Para defender essa concepção de kátharsis que se encontra no âmbito do prazer estético, da moralidade e do reconhecimento dos casos singulares, pretendo seguir a linha de argumentação que autores como Stephen Halliwell e Martha Nussbaum seguem, além de algumas considerações de Marco Zingano.

\section{Três interpretações da kátharsis trágica}

A kátharsis, na Poética, desenvolve o papel de certo efeito gerado pelos sentimentos de temor e piedade que a imitação de uma ação de caráter elevado provoca em seus espectadores. Tentar compreender o sentido de kátharsis é tentar entender o que esse efeito possibilita ao público (leitor ou espectador) de uma tragédia, de que natureza é este processo e, diretamente dependente da natureza de tal processo, como será o resultado do mesmo nos espectadores. Por exemplo, se entendermos o termo em questão como purificação, teremos de admitir um resultado e um tipo de espectador diferentes dos outros casos: como veremos a seguir, a noção de purificação compreende a noção de que a kátharsis trágica está ligada ao frenesi religioso e, portanto, a um público "não educado" que não discrimina entre a arte poética e um ritual religioso, além também de ser um público suscetível às emoções em um nível patológico ${ }^{3}$ - estando muito longe da noção de "homem educado" que Aristóteles tem como o modelo de público de uma tragédia. Isso mostra que, dependendo do que tomarmos como interpretação para o termo kátharsis, teremos de inferir um resultado de tal processo e um público que entram claramente em desacordo com uma ou várias noções aristotélicas.

\subsection{A kátharsis trágica como purgação ou cura medicinal}

\footnotetext{
3 "Para emoções como piedade e temor, ou ainda entusiasmo, que existem de maneira mais forte em algumas almas, e têm mais ou menos influência sobre elas." Op cit. 
A premissa básica para uma interpretação do tipo (1) é de que a kátharsis é a cura para alguma patologia ou algum mal. Seria, assim, um processo através do qual o espectador tem suas emoções de temor e piedade "purgadas" de seu constituinte psicológico, i.e., essas emoções são "retiradas" do público, pelo menos na medida em que são nocivas a ele, assim livrando-o do efeito maléfico que possam ter. Zingano explica de maneira muito clara este processo e os "riscos" que ele pode conter para a interpretação do texto e da arte poética em geral:

Estamos, assim, no âmbito de uma teoria homeopática da catarse tipicamente psicopatológica: exacerbando as emoções de piedade e medo com mais piedade e medo naqueles que têm cronicamente tais afecções, obtém-se finalmente sua remoção ou purgação. Bernays seguramente fez jus ao desejo de Goethe de separar a arte da moral, mas isto ao preço de colocá-la perigosamente sob a insígnia do patológico. (ZINGANO, 1998, p. 4)

A noção de purgação costuma ser compreendida em consonância com o capítulo 7, livro VIII da Política ${ }^{4}$, em que Aristóteles analisa a importância das "melodias catárticas" para curar por meio do frenesi religioso, e, por analogia, com a noção biológica de purgação apresentada nos Problemas ${ }^{5}$, segundo a qual a ideia de purgação vem da introdução de uma substância estranha, razão pela qual o corpo animal acaba por expelir, junto dela, todas as outras substâncias nocivas presentes. O que Lear interpreta, ao contrastar as duas noções, é que o sentido biológico de "purgação" está quase em um nível de analogia para instanciar essa cura que é apresentada na Política VIII, 7 que, segundo ele, é: "uma cura para uma condição emocional patológica: [a] tragédia ajuda a expulsar ou se livrar de emoções doentiamente reprimidas ou elementos emocionais nocivos." (LEAR, 1992, p. 316, grifo nosso) ${ }^{6}$.

Por sua vez, para Lear, parece haver pelo menos duas razões para negar tal apresentação. Será tratada aqui apenas a de que ele se ocupa com mais convicção no

\footnotetext{
$4 \quad$ Op. cit.

"As drogas não estão conectadas - elas fazem o seu percurso para fora levando consigo qualquer coisa que fica em seu caminho: isso é chamado de purgação.” (Problemas 42, 864a34).

$6 \quad$ No texto original: "a cure for an emotionally pathological condition: tragedy helps one to expel or get rid of unhealthily pent-up emotions or noxious emotional elements." 
artigo, cuja defesa implicará a compreensão de sua tese mais geral para uma interpretação da kátharsis. O argumento baseia-se diretamente em uma evidência textual do trecho já apresentado da Política e consiste em mostrar que (1) o que se segue da interpretação da kátharsis como purgação não é compatível com (2) a afirmação aristotélica de que a kátharsis acontece com todos aqueles que são influenciados pelo temor e pela piedade, e, em geral, por quaisquer "emoções naturais" (1342a11-13).

Em (1), temos a condição de que purgação implica um estado patológico. Portanto, se aceitarmos que se trata de uma purgação a kátharsis trágica, estaremos utilizando-nos do pressuposto de que tal efeito da tragédia seja o mesmo efeito proporcionado pelas "melodias catárticas" da Política para curar através do êxtase religioso, que é considerado por Aristóteles algo que sucede àqueles com alguma afecção psicopatológica. Se tivermos isso como pressuposto, logo teremos também a noção de que o público das tragédias é o mesmo público que sofre de alguma patologia. Ora, a implicação de (1) é simplesmente incompatível com (2), pois (2) compreende também, no momento em que sugere a afecção de todos os homens pelas emoções naturais (afinal, é totalmente absurdo falar de alguém sem quaisquer emoções na filosofia de Aristóteles), que o homem educado seja afetado pela kátharsis. Mais uma vez, chegando a este problema interpretativo, é preciso salientar que o homem educado possui um caráter estável (bons hábitos) que, por sua vez, não pode estar condicionado a nenhum estado patológico ou nocivo. A estabilidade do caráter do homem educado também nos garante que seus sentimentos estejam fundamentados em crenças estabelecidas racionalmente, o que também é um fator importante para não aceitarmos que este mesmo caráter seja afetado por quaisquer patologias. ${ }^{7}$

\subsection{A kátharsis trágica como purificação ritualística}

A noção de kátharsis aqui é entendida em analogia como efeito dos rituais religiosos e também das melodias catárticas já mencionadas. Neste sentido, a tragédia é entendida como um ritual, e enfatizado seu caráter performático, com efeitos e público 7 Cf. Nussbaum: "Uma emoção aristotélica típica é definida como a combinação de um
sentimento de prazer ou dor com um tipo particular de crença sobre o mundo." (2009, p. 336). 


\section{Mariane Farias de Oliveira}

análogos aos dos rituais religiosos (HALLIWELL, 1998, p. 186). Tais práticas religiosas compreendiam a purificação de algum sofrimento profundo através do prazer suscitado por melodias e procedimentos próprios do ritual.

Mesmo que seja deixada de lado a objeção de que nada pode ser nem purgado (como visto acima) nem purificado - já que isso também consistiria em algo nocivo contido no público de uma tragédia -, visto que este é, por excelência, composto por homens educados, ainda há o seguinte argumento contra a interpretação da kátharsis como purificação: a kátharsis é experimentada pelo homem educado quando está no teatro, mas suas emoções não são, em sentido algum, impuras (LEAR, 1992, p. 318). Isso seria aproximadamente uma variação do argumento de (1) sobre a purgação, mas atentando para um elemento a mais: a noção de ritual considera a tragédia como mera performance, deixando de lado o conhecimento do mito. A pertinência dessa diferença está na afirmação de Aristóteles, ao final da Poética, de que o conhecimento do mito pode se dar através do texto dramático ou da performance dramática: "Acresce que a tragédia, mesmo não acompanhada da movimentação dos atores, produz seu efeito próprio, tal como a epopéia, pois sua qualidade pode ser avaliada apenas pela leitura." (1462a11-13, grifo nosso).

Dessa forma, para desconsiderarmos a possibilidade de interpretação da kátharsis como purificação das emoções de temor e piedade, além do argumento da impossibilidade de purgar ou purificar algo do homem virtuoso, também temos de considerar que a noção de purificação se dá na performance. Mas como, se pudesse ser considerada essa hipótese, aconteceria a purificação? Comentadores que defendem tal interpretação afirmam que a purificação seria o ato de abolir as emoções de temor e piedade do aparato psicológico da audiência - atribuindo, assim, um caráter estritamente negativo para tais emoções, na medida em que causariam sofrimento ao público -, através do deleite (alívio) que a kátharsis proporcionaria. Esse deleite, além de ser o meio pelo qual se extingue o sofrimento do espectador, também seria a instância última da transformação de tais emoções, o "resultado" da kátharsis. Tal definição pode ser vista em Eduard Muller: "Quem pode duvidar de que a purificação da piedade, medo e outras paixões consiste, ou pelo menos está intimamente conectada, na transformação da dor que é engendrada no prazer?"»8 (MULLER, Eduard. Theorie

$8 \quad$ No original: "Who can any longer doubt that the purification of pity, fear, and other passions consists in, or at least is very closely connected with the transformation of the pain that engendered them 
der Kunstbei den Alten, vol. 2, p. 62 apud LEAR, 1992, p. 319).

A partir da leitura de Muller, mesmo se tomarmos o temor e a piedade em seu caráter polutivo ou nocivo, ainda teremos a questão: será que se trata, de fato, de uma transformação em prazer? Como isso se daria, segundo o texto de Aristóteles? Também no mesmo trecho da Poética em que analisaremos tais aspectos há uma evidência textual para o problema da existência da kátharsis apenas através da performance.

Nos capítulos 13 e 14 Aristóteles argumenta sobre a construção de um enredo trágico e sobre como o temor e a piedade surgem de um bom enredo. No capítulo 13, são dadas todas as condições "do que precisa acontecer" para que uma tragédia atinja seu efeito, isto é, todas as condições para uma boa trama. Ao definir a situação trágica por excelência, Aristóteles afirma que:

Para que uma fábula seja bela, é portanto necessário que ela se proponha um fim único e não duplo, como alguns pretendem; ela deve oferecer a mudança, não da infelicidade para a felicidade, mas, pelo contrário, da felicidade para o infortúnio, e isto não em conseqüência da perversidade da personagem, mas por causa de algum erro grave, como indicamos, visto a personagem ser antes melhor que pior. (1453a10-15).

Esta seria a "prescrição" para a constituição de um bom enredo, de acordo com a observação que Aristóteles faz dos tragediógrafos (como Eurípides) e também do que se pode aprender olhando para o passado: os bons mitos, que mantêm sempre esta estrutura que pode ser reconhecida, são aqueles que persistem (1453a17-21).

É tendo em vista exatamente essa constituição da trama trágica que Aristóteles inicia o capítulo 14 afirmando que o medo e a piedade são corretamente apresentados não pelos elementos do espetáculo, mas para a constituição do enredo, ou seja, da íntima conexão das ações que o perfazem: “O terror e a compaixão podem nascer do espetáculo cênico, mas podem igualmente derivar do arranjo dos fatos, o que é preferível e mostra maior habilidade no poeta." (1453b1-3). Em seguida, contrariando a perspectiva de Muller e reiterando a leitura de Lear, Aristóteles afirma que há um prazer específico da tragédia (oikeîa hēdoné), o prazer que é inerente ao efeito dos sentimentos de piedade e temor. Este é o único que deve ser procurado pelo espectador e que, de fato, é proporcionado pelo enredo trágico (1453b 7-10). No entanto, é difícil pensarmos em "transformação", quando Aristóteles pressupõe um prazer intrínseco (ou 


\section{Mariane Farias de Oliveira}

inerente) à arte trágica. Uma transformação, como Muller propõe, teria de partir de um sofrimento intrínseco às emoções trágicas em direção a um prazer compreendido nesses mesmos sentimentos, e não do enredo. Logo, pelas evidências textuais (cf. definição do sentimento de piedade na Retórica ${ }^{9}$, por exemplo, que necessariamente compreende dor), o que nos é dado é que, durante uma tragédia que contenha um bom enredo, sentimos prazer, porque este é inerente à cognição da estruturada trama trágica, e não por qualquer tipo de transformação no que é característico das emoções.

Sobre a performance, ainda, o mesmo capítulo trata brevemente disto, afirmando que as emoções produzidas por um bom enredo não devem ser concebidas unicamente pelo espetáculo ou performance trágica, i. e., do movimento externo, simplesmente mecânico do prazer hedonista do entretenimento, pois isso seria "alheio à arte" (1453b 6-7). Neste trecho, Aristóteles tem em vista a noção de que não se deve abusar dos elementos cênicos para tentar provocar medo e piedade no público, mas sim fazê-lo através da construção de uma boa trama, que proporciona um movimento interno mediado pela cognição e pela imaginação. Este sentido difere bastante do que apresentamos do capítulo 26, que é o que é mais fundamental para defender a tese de que a kátharsis, ou o efeito da tragédia, existe para além do espetáculo, conforme já foi argumentado aqui. Porém, mesmo havendo tal diferença entre os argumentos, a consideração do capítulo 14 sobre a performance também faz-se importante para refutar a tese interpretativa de Muller a respeito da purificação através da transformação que ocorreria durante o espetáculo.

\subsection{A kátharsis trágica como educação das emoções}

Recentemente, há uma tendência entre os comentadores - Lessing, Leon Golden, Humprey House, Martha Nussbaum - em delegar à kátharsis um sentido de clarificação ou educação dos sentimentos. Estes autores não parecem colocar em questão o problema do homem educado, e para eles tal educação ou clarificação estaria diretamente ligada a uma função moral, tomando a moralidade tal como compreendida na filosofia aristotélica, e se daria através do processo de "habituação" (a imposição de

\footnotetext{
$9 \quad$ Na Ret. (1385b13), Aristóteles define a piedade como "um sentimento de dor diante de um mal aparente ou destrutivo, que acontece a quem não o merece." 
hábitos). A tragédia mostraria a todos capazes de determinado processo de cognição, proporcionado pela unidade da tragédia, o que é suscetível de lhes acontecer e como agir virtuosamente diante disso. A ideia de "mostrar" aqui também é importante, pois nisso a arte diferencia-se (e complementa) do que pode ser aprendido pela investigação filosófica. A arte poética exemplifica inúmeros casos e mostra, diretamente, as circunstâncias e o agir virtuoso. É este exatamente o sentido de educar diante de determinadas circunstâncias que não estão instanciadas na educação moral que o espectador já tenha recebido.

Neste sentido, a educação pelo hábito acontece na tragédia através das emoções de temor e piedade. Ao assistir às ações que constituem o enredo, tanto jovens em processo de educação como homens já educados, deveriam observar e aprender, através de uma kátharsis, o que é adequado fazer em casos concretos do exercício da virtude, os casos particulares que não podem ser determinados ou ensinados a não ser a partir da experiência. Isso tornaria mais ampla a gama de experiências do agente moral. Desta forma, sim, pode-se afirmar que a tragédia é pelo menos parte da educação moral.

Porém, neste argumento há um problema: a tragédia não pode ser toda ela uma educação moral, pois há algo que não se subsume a tal educação, que é o "prazer específico da tragédia" (oikểa hēdoné) que Aristóteles menciona no capítulo 13 da Poética (1453b 7-10).

O prazer da tragédia parece estar diretamente amparado em nossa cognição, um tipo específico também de cognição, no sentido de "notar", perceber instantaneamente, através da surpresa reveladora que o mȳthos nos mostra diretamente. Vamos tomar a passagem do capítulo 4 da Poética como evidência textual para discutirmos o que Aristóteles parece entender da relação entre cognição e prazer. Nussbaum afirma que, nessa passagem, Aristóteles propõe que "nosso interesse na mímesis é um interesse cognitivo, um interesse em aprender" (2009, p. 340):

A prova é-nos visivelmente fornecida pelos fatos: objetos reais que não conseguimos olhar sem custo, contemplamo-los com satisfação em suas representações mais exatas. Tal é, por exemplo, o caso dos mais repugnantes animais e dos cadáveres. A causa é que a aquisição de um conhecimento arrebata não só o filósofo, mas todos os seres humanos, mesmo que não saboreiem tal satisfação durante muito tempo. Os seres humanos sentem prazer em olhar para as imagens que reproduzem objetos. A contemplação delas os instrui, e os induz a discorrer sobre cada uma, ou a discernir nas imagens as pessoas deste ou daquele sujeito conhecido. Se acontece alguém não ter visto ainda o original, não é a 


\section{Mariane Farias de Oliveira}

imitação que produz o prazer, mas a perfeita execução, ou o colorido, ou alguma outra causa do mesmo gênero. (1448b 12-20).

É preciso atentar a alguns pontos da passagem para entendermos melhor como se dá o prazer no conhecimento do mito que está na base do enredo da tragédia: (1) Aristóteles estende a noção de deleite na imitação a todos os homens, inclusive não educados, embora não possam ter um "aproveitamento total" do que lhes é apresentado; (2) a apreensão sensível de superfícies e cores que compõem a imitação proporciona aprendizado, que, por sua vez, proporciona prazer ao homem quando este adquire a capacidade de definir e apontar algo; (3) por fim, é preciso ter conhecido o original da imitação para ter reconhecimento e, com isso, sentir prazer na mímēsis (1448b 12-20).

Tais observações não dizem respeito diretamente à tragédia, como podemos notar no texto. Porém, isso parece se estender à análise da arte trágica, quando no que é chamado de original da mímēsis temos o mito e no que compõe a imitação temos a representação dramática deste.

No que concerne ao reconhecimento, parece plausível que este possa ser dado em graus, ou seja, podemos não conhecer totalmente o original, mas quanto mais o conhecemos mais deleite sentimos ao poder apontar e definir o que acontece na ação empreendida no drama. Dessa forma, Aristóteles aqui parece reforçar a relação direta entre conhecimento e prazer que apresenta em outras obras (como em argumentos apresentados em Metafisica I e Ética Nicomaqueia X 7).

Dada a interpretação de tal evidência textual, temos, então, uma razão forte para explorar melhor onde se encaixa e como funciona o prazer específico da tragédia advindo da cognição da ação trágica contida no mȳthos. Esse conhecimento se revela na metábole (reviravolta) - que, por sua vez, é a estrutura especificamente trágica do mito.

As considerações de Halliwell (1998, p. 199) parecem tomar como ponto central o funcionamento do prazer específico da tragédia como cerne do que seja possível clarificar ou educar de nossas emoções, ao dizer que: "[...] com uma minoria dos intérpretes modernos, que a kátharsis trágica de alguma maneira conduz a um 
alinhamento ético entre emoções e razão"10 e que "tende a harmonizá-las [as emoções] com nossas percepções e juízos sobre o mundo" ${ }^{\text {"11 }}$. Mas Halliwell, no mesmo parágrafo e como conclusão de seu capítulo a respeito das emoções trágicas, também assume que: "[a] kátharsis deve também estar intimamente associada ao prazer derivado do gênero [...], [e] consiste na compreensão de uma mesma ação que é o foco de todas as emoções"12 (1998, p. 201). Dessa maneira, defendendo o argumento de Halliwell, - que será de total relevância para o tópico seguinte -, podemos concluir que a tragédia admite que a kátharsis seja, de fato, uma via de acesso à educação moral, mas é condição necessária, para tal, que o agente tenha a experiência do prazer específico do trágico, ou seja, o prazer advindo da cognição da ação única, a ação para qual estão voltadas as emoções.

\section{Kátharsis: conhecimento e prazer}

Assim, precisamos analisar como podemos falar da kátharsis a partir de uma noção que esteja de acordo com o prazer específico da tragédia. A partir desta análise, mais tarde também refutaremos o argumento de Lear de que o homem educado não poderia ter ainda algum tipo de educação em algum sentido. Se olharmos mais atentamente o trecho da Política em que aparece a noção de kátharsis, poderemos ver que Aristóteles delegou à mousikế, que inclui a poesia e o drama, as três funções já mencionadas: educação, entretenimento e entretenimento educativo (diagōgé). A noção de diagōgé consiste em dizer que não é qualquer tipo de entretenimento que pode satisfazer plenamente o homem, mas apenas a mousiké que for responsável pela união do prazer a uma espécie de "beleza moral"13, pois contribui para o caráter e para a inteligência. A diagōgé é, por excelência, o modo de entretenimento dos homens adultos e educados: quando Aristóteles apresenta as três instanciações da mousiké, ele se refere à diagoggé ao sugerir que "[...] devemos argumentar que a mousiké conduz à

10 No original: "[...] with a minority of modern interpreters, that tragic katharsis in some way conduces to an ethical aligment between the emotions and the reason".

11 No original: "[...] tends to harmonize them with our perceptions and judgments of the world."

12 No original: "[...] katharsis must also be intimately associated with the pleasure derivable from the genre [...], arises from the comprehension of the same action which is the focus of the emotions."

13 Expressão retirada de: TATARKIEWICZ, Historia de la Estetica, 1987. 


\section{Mariane Farias de Oliveira}

virtude, $[\ldots]$ ao dizer que ela contribui tanto para o gozo do lazer quanto para o cultivo mental [...]" (1339a21-26).

A noção de diagōgé, aliada ao que foi visto como o sentido de educação da tragédia constituído de um prazer específico, nos traz a seguinte pergunta: a diagōgée, a beleza moral dos homens adultos e educados, poderia ser uma via de acesso para a interpretação da kátharsis como educação das emoções? Assim, a kátharsis poderia ser entendida como a experiência que é suscitada pelos sentimentos de temor e piedade e que gera uma educação prazerosa em relação a estes sentimentos. A kátharsis não pode ser a educação prazerosa em si, pois esta é apenas uma função da mousikế, neste caso do drama, mas interpretar a kátharsis associada a esta função possibilita a compatibilização da função educativa que a tragédia deve exercer em seu público e o prazer específico do drama que é forçoso notar no capítulo 13. Além disso, através dessa compatibilização, também está explicado por que o homem educado pode, em certo sentido, ainda ampliar suas experiências com vistas às ações virtuosas. Tal compatibilização permite, por fim, que o conhecimento e a dramatização do mito sejam instanciados na educação moral e estética do homem.

\subsection{Como acontece a educação das emoções e o que são as emoções trágicas}

Para uma tomada de posição em relação a todas as questões levantadas, acreditamos que devemos responder à pergunta: então o que, a partir de uma educação prazerosa das emoções, nos é ensinado no enredo trágico?

Pelo trajeto até então delineado, é forçoso notar que a kátharsis, entendida nessa relação de compatibilização com uma educação prazerosa, consegue fazer com que o público educado possa analisar em casos concretos o exercício da virtude e obter uma educação de sua sensibilidade para reconhecer estes casos.

Para pensar essa relação há de se ter em mente, também, que a constituição dos eventos trágicos e de sua estrutura, para Aristóteles, são apresentadas de maneira totalmente racional. Para Halliwell (1998, p. 187), no enredo trágico está

Implícito nisto a premissa que a piedade e o medo dependem de um conjunto de circunstâncias inteligível, e assim, no caso do drama trágico, de uma sequência completa de ações e eventos, para satisfazer as 
exigências de unidade $\left[\ldots . .{ }^{14}\right.$

Podemos entender, a partir disso, que a tragédia "educa" no sentido de reestabelecer uma ordem racional nas e para as emoções no momento em que o homem educado sai do teatro ou termina a leitura de uma tragédia. A situação trágica por excelência apresenta homens afortunados cometendo erros terríveis (harmatía) diante de profundas transformações a que a Fortuna submete suas vidas. Segundo Halliwell (1998, p. 182) é diante dessa situação que a arte trágica reestabelece as crenças que fundamentam as emoções do espectador ao fazer com que ele conceba a iminência de algum acontecimento ou experiência terrível tal qual pode suceder em sua vida, donde surge o temor, e o "educa" no sentido de prepará-lo para os "casos concretos", acontecimentos específicos em que é preciso exercer determinada virtude moral. Nussbaum (2009, p. 340), ainda afirma que é através da recepção das emoções trágicas por parte do espectador e a observação da própria recepção (reflexão) que este espectador pode desenvolver uma espécie de "auto-entendimento", um conhecimento mais profundo acerca das razões que sustentam suas crenças sobre o que é digno de piedade e do que faz com que se atemorize. Por isso, também, que mesmo o homem educado - e principalmente ele, pois consegue reconhecer as circunstâncias do ato virtuoso - necessita de tal educação, pois ela é uma educação que se dá através de casos concretos. Ainda que esses casos apresentem certa universalidade causal - e que o prazer específico se dê em relação ao reconhecimento do particular em relação ao universal -, eles são concretos na medida em que estão circunstanciados em situações e caracteres particulares, proporcionando ao homem educado ainda mais experiência diante de novas circunstâncias que lhes são apresentadas.

Quanto à piedade, a outra emoção que suscita o efeito trágico para Aristóteles, é justamente através dela que se torna possível conceber a iminência de um acontecimento, pois o espectador coloca-se no lugar de determinada personagem, sofrendo também, mesmo que de maneira "performativa", suas afecções.

Vemos em duas passagens de Halliwell a introdução da noção de empatia tomada como sinônimo de piedade, pois gera compaixão, neste processo:

Isso está de acordo com esse viés teórico de que a piedade e o medo aristotélicos têm um claro conteúdo cognitivo e representam não apenas

14 No original: "Implicit in this is the premise that pity and fear depend on an intelligible conjunction of circumstances, and so, in the case of tragic drama, on a comprehensive sequence of actions and events, to satisfy the requirements of unity [...]." 
meros impulsos, mas consequências emocionais das percepções de que certas coisas são ou não são de certa maneira: que o sofredor, ou o sofredor em perspectiva, é em boa medida inocente, que ele é suficientemente como nós tal que seja possível simpatizar com a natureza de sua situação, que poderíamos imaginar a nós mesmos ou a quem conhecemos em uma posição parecida, e assim por diante.

E também: (HALLIWELL, 1998, p. 195) ${ }^{15}$.

Eu tentei mostrar que essa noção de simpatia, que subjaz tanto à piedade quanto ao medo, não é um instinto vagamente humanitário: é a capacidade de reconhecer uma semelhança entre si mesmo e o objeto de suas emoções, uma semelhança que importa ao objeto um sentido tal que alguém poderia se imaginar sofrendo as mesmas coisas ele mesmo. (HALLIWELL 1998, p. 196). ${ }^{16}$

Dessa maneira, Halliwell torna claro que é pelo exercício da empatia que a arte trágica torna possível que a educação das emoções e das virtudes morais se dê em relação ao homem, pois em um enredo trágico ele pode visualizar casos específicos da prática das virtudes. A empatia é a pedra de toque da educação das emoções, pois cria, através do prazer estético que a relação entre espectador e personagem (o primeiro se colocando no lugar no segundo, experimentando sentir suas emoções e aflições), uma sensibilidade moral que é fundamental para ação, embora seja necessário, também, certo distanciamento para a reflexão diante do agir.

\subsection{A compreensão dos "casos concretos"}

Uma leitura diferente do papel aqui atribuído à tragédia, i.e., educar a sensibilidade do espectador para os casos concretos, pode ser vista em Zingano (2009), que abranda essa educação para todos os casos de deliberação, pois, em sua leitura, dado que todo o caso de ação é um caso concreto, ou singular, não há referência à experiência do prazer específico da tragédia:

La fractura entre arte y decisión práctica vuelve a colación: mientras que el arte se basa em métodos y rutinas de decisión, la acción se ve

15 No original: "It accords well with this theoretical slant that Aristotelian pity and fear have a clear cognitive content, and represent not mere impulses but the emotional consequences of perceptions that certain things are or are not so: that the sufferer, or prospective sufferer, is largely innocent, that he is sufficiently like us for it to be possible to sympathize with the nature of his plight, that we could imagine ourselves or those related to us in an equivalent position, and so on."

$16 \quad$ No original: "I have tried to show that this notion of sympathy, which underlies both pity and fear, is not a vaguely humanitarian instinct: it is the capacity to recognise a likeness between oneself and the object of one's emotions, a likeness which imports with it a sense that one could imagine suffering such things one self." 
impregnada de una imprecisión que solo se esclarece al interior de las circunstancias em las que transcurre cada acción particular. (ZINGANO, 2009, p. 16)

É importante notar que essa leitura está demasiado vinculada aos argumentos de Aristóteles da Ética Nicomaqueia, mas é de interesse fundamental para este estudo, pois a partir dela podemos compreender melhor de que se tratam esses "casos concretos" ou particulares para os quais o mito que está na base do enredo, instanciado na tragédia e através da kátharsis, educa.

Vemos nas considerações de Zingano sobre o papel do mito na filosofia de Aristóteles que, na Ética Nicomaqueia (1106b 15-16), pode haver a interpretação de uma espécie de imprecisão no cálculo que o prudente faz quando delibera:

La virtud [...] busca el término médio así como el arquero apunta al blanco. Hay una zona imprecisa cuya obtención ya no puede depender de procedimentos deductivos precisos; el prudente procede bien por médio del cálculo, pero, al igual que el arquero que apunta al blanco, su calcular seda por aproximación. Hay algo aqui que, permanecendo en el campo de la razón, escapa, sin embargo, a los rígidos procedimientos de la deducción. (ZINGANO, 2009, p. 15).

Para Zingano, é justamente nesta "lacuna da razão", na imprecisão do cálculo dedutivo do agente que o mito, sempre compreendido como instanciado no enredo, em uma análise especulativa do texto, tem um papel na ação do homem prudente. Os valores que o prudente precisa calcular a fim de deliberar não são dados em blocos, em simetria. É preciso que seja feita uma escolha. Diante de várias escolhas, o prudente é aquele que toma a melhor escolha para agir. Obviamente a escolha é acompanhada da razão, mas não somente dela.

Zingano não conclui de que maneira o mito exerce essa função, mas na investigação aqui empreendida é importante apresentar como Aristóteles parece entender essa imprecisão nas deliberações da ação e como, especulativamente, a tragédia poderia suprir tal lacuna através da educação do agente.

\section{Considerações finais}

O que vimos até agora mostra que a kátharsis pode ser entendida como um “jogo" representativo que é jogado no teatro a fim de educar seus espectadores para quando saírem de lá. Ou seja, a educação prazerosa mostra ao espectador, através da 


\section{Mariane Farias de Oliveira}

possibilidade de acontecer-lhe algo terrível, de perder um status afortunado, que é representado no teatro, como agir na "vida real", fora da representação poética.

No entanto, Bergeret (2013) afirma que obras literárias não são instrumentos neutros para a exploração ética. É claro que a tragédia também comporta performance, mas tal afirmação parece poder se estender a qualquer obra poética, se pensarmos como Nussbaum, quando sugere que "todo estilo é em si mesmo uma tese" (1992, p. 20). Nussbaum escreve isso para defender que o conteúdo e a forma são inseparáveis em uma obra poética, são escolhas do autor e devem ser assim respeitadas como uma unidade. Se qualquer aspecto formal é modificado ou ignorado, a obra é completamente modificada, é desrespeitada e, por sua vez, rompida sua unidade. Uma exploração somente moral da tragédia leva em conta somente seu conteúdo, e é por esta razão que não respeita o estatuto trágico do enredo. Por isso a passagem em que Aristóteles comenta que há "um prazer específico da tragédia" em sua cognição é tão importante para conferir uma interpretação que compatibiliza as dimensões éticas e estéticas de análise do efeito da tragédia (kátharsis) e da natureza dessa educação das emoções no espectador.

$\mathrm{Na}$ educação das emoções, por um lado, a sensibilidade que é refinada por essa educação é afetada pelo prazer cognitivo da arte poética, que hoje invariavelmente interpretamos como subsumida ao escopo da estética. Por outro lado, o refinamento dessa sensibilidade é justamente para o reconhecimento da ação virtuosa diante de diversas circunstâncias, que tanto para Aristóteles como para nós se encontra no escopo de um aprendizado moral. A tragédia é, portanto, o ponto de encontro entre a técnica (a arte poética) e a moralidade (as ações virtuosas) na obra de Aristóteles - e foi justamente a interpretação da kátharsis como uma educação prazerosa das emoções o que nos permitiu aprofundar nossa compreensão a respeito da natureza da tragédia e suas implicações. 


\section{Referências}

ARISTOTLE. The complete works of Aristotle (v. II). Princeton: Princeton University Press, 1984.

BERGERET, Lucy. L'expressivité morale du texte littéraire, [online]. 2013. Disponível em: http://www.implications-philosophiques.org/actualite/une/lexpressivite-morale-dutexte-litteraire-22/, acesso em 10/08/2013.

ELSE, Gerald. Introduction, translation and notes. In: ARISTOTLE. Poetics. Michigan: University of Michigan, 1970.

HALLIWELL, Stephen. Aristotle's Poetics. Chicago: The University of Chicago Press, 1998.

LEAR, Jonathan. "Katharsis". In: RORTY, A. (ed.). Essays on Aristotle's Poetics. Princeton: Princeton University Press, 1992.

NUSSBAUM, Martha. A Fragilidade da Bondade. São Paulo: Martins Fontes, 2009.

NUSSBAUM, Martha. Love's Knowledge: Essays on Philosophy and Literature. Oxford: Oxford University Press, 1992.

ZINGANO, Marco. "Katharsis poética em Aristóteles". Síntese - Revista de Filosofia, Vol. 24, n. 76, 1997.

ZINGANO, Marco. Soberbia de la razón y uso práctico: notas sobre el destino del mito en el pensamiento clásico ateniense. In: Areté: Revista de Filosofia, Vol. 21, n. 2, 2009. 